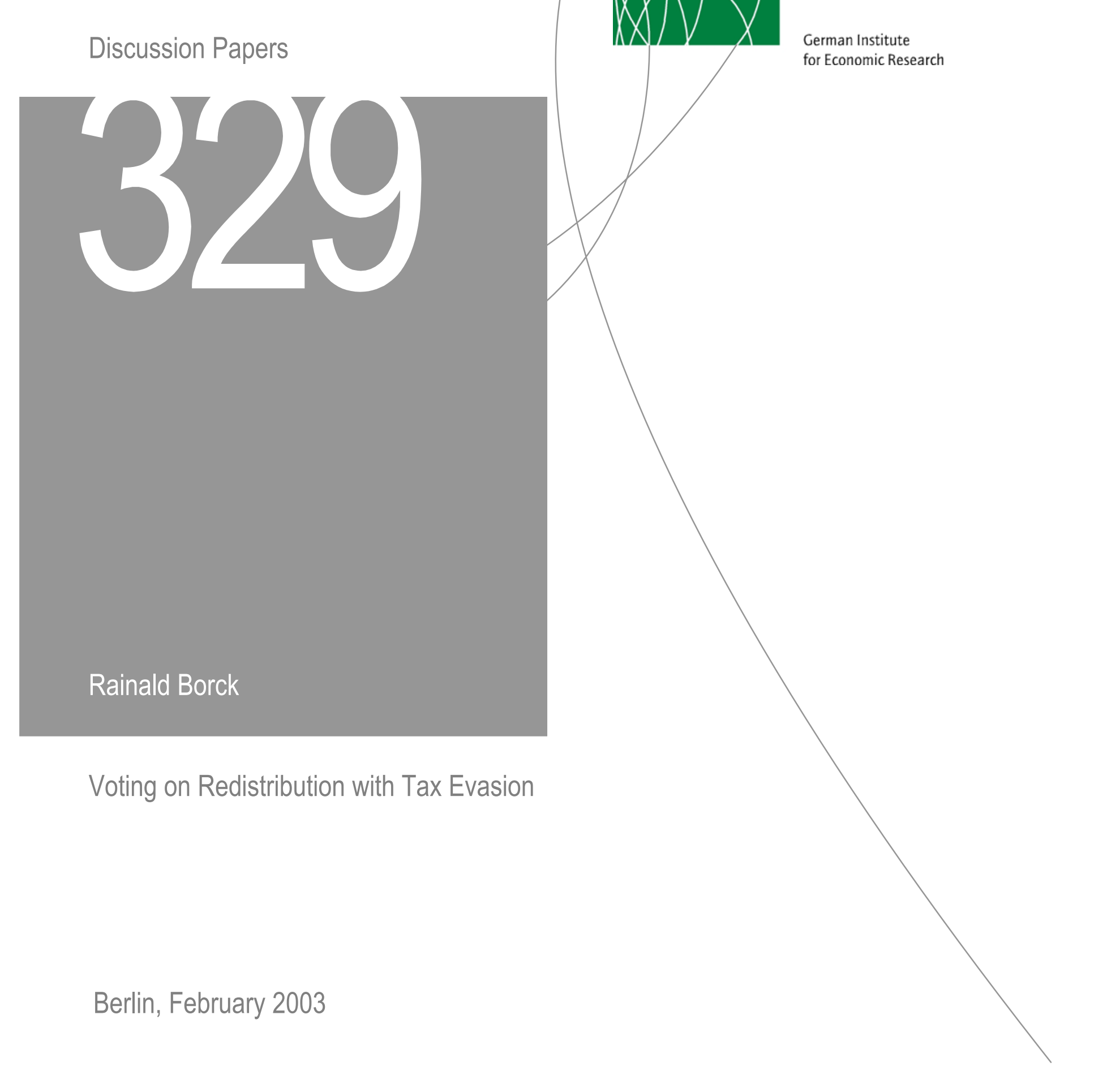


Opinions expressed in this paper are those of the author and do not necessarily reflect views of the Institute.

\section{DIW Berlin}

\section{German Institute}

for Economic Research

Königin-Luise-Str. 5

14195 Berlin,

Germany

Phone +49-30-897 89-0

Fax +49-30-897 89-200

www.diw.de

ISSN 1619-4535 


\title{
Voting on Redistribution with Tax Evasion
}

\author{
Rainald Borck* \\ DIW Berlin
}

February 18, 2003

\begin{abstract}
This paper analyzes voting on a linear income tax which is redistributed lump sum to the taxpayers. Individuals can evade taxes, which leads to penalties if evasion is detected. Since preferences satisfy neither single peakedness nor single crossing, an equilibrium may not exist. When it does exist, it may have interesting properties, in particular, the poor and the rich may form a coalition against the middle class.
\end{abstract}

JEL classification: H26, D72.

Keywords: Tax evasion, redistribution, voting.

*Address for correspondence: DIW Berlin, 14191 Berlin, Germany, Tel. +49-30-89789166, Fax +49-30-89789-114, Email rborck@diw.de 


\section{Introduction}

Progressive income taxes are generally seen as a device to redistribute income from the rich to the poor. This idea is at the heart of the optimal taxation literature (Mirrlees, 1971) as well as most contributions in the political economics tradition (Romer, 1975; Roberts, 1977; Meltzer and Richard, 1981). However, the incidence of the tax depends not on the progressivity of the tax schedule, but on the progressivity of tax payments. These, however, are influenced by individual decisions, such as how much to work and save, and the decision of how much taxes to pay. In this paper, we ask the following question: How does tax evasion influence the outcome of a game where individuals vote on an indirectly progressive income tax?

The paper builds on and combines two distinct strands of literature. On the one hand, Romer (1975), Roberts (1977) and Meltzer and Richard (1981) have analyzed voting on indirectly progressive tax schedules. In this type of model (the "RRMR" model), if voters can be ordered by their income level, the voting outcome corresponds to the preferred tax rate of the median income earner. For instance, if labor income is monontonically increasing in the wage rate, the equilibrium corresponds to the optimum of the median wage earner. In all of these models, taxes are paid for sure. On the other hand, Allingham and Sandmo (1972), Yitzhaki (1973), and others have analyzed the individual tax evasion decision. In their models, however, taxes are treated as exogenous. ${ }^{1}$

A few papers have studied the interrelation of tax evasion and public spending. The interplay between public goods supply and tax evasion is studied by Cowell and Gordon (1988) and Falkinger (1991). Cowell and Gordon (1988) look at the effect of public goods on tax evasion, while Falkinger (1991) analyzes how evasion affects the optimal supply of public goods. Slemrod (1994) analyzes the impact of avoidance on tax progression in an optimal taxation framework. He finds that increased possibility of avoidance for the rich makes the income tax less effective in redistribution and thus reduces the optimal linear tax rate. Roine (1999)analyzes voting on redistribution with tax avoidance, which is legal. Hence, enforcement plays no role in his model. Two experimental studies on tax evasion and voting are presented by Alm, Sanchez, and de Juan (1995) and Feld and Tyran (2002). Their focus,

\footnotetext{
${ }^{1}$ See Cowell (1990), Andreoni, Erard, and Feinstein (1998), and Slemrod and Yitzhaki (2000) for surveys of the tax evasion literature.
} 
however, is on the influence of voting on social norms of tax compliance.

Tax evasion has an impact on the voting game which is not trivial. The RRMR model assumes that pre-tax income is monotonic in the wage rate. This implies that voters can be ordered such that richer individuals prefer lower tax rates than poorer voters. The equilibrium corresponds to the preferred tax rate of the median wage earner. In the present model, the ordering of preferences depends on taxed income which depends on the evasion decision. Richer voters may have lower taxed income than poorer ones if they evade at lower tax rates. Hence, the ordering of preferences may be reversed. This implies that an equilibrium may not exist. However, when it does, it may not be of the simple "rich prefer lower taxes than poor" type. In particular, it may be that the rich and poor prefer higher taxes, at the margin, while the middle class voters prefer lower taxes.

In models of public provision of private goods, there are also interesting properties of voting equilibria. In particular, Epple and Romano (1996b) Epple and Romano (1996a) show that equilibria may have the property that the rich and poor vote against the middle class, whereas Fernandez and Rogerson (1995) argue that voting may lead to public provision of education which benefits the rich and middle class at the expense of the poor.

The paper proceeds as follows. The next section outlines a simple model where voters are risk neutral. Section 3 describes the voting game. In section 4 we describe the possible outcomes of the game. Section 5 discusses the case of risk aversion. With the use of an example, it is shown that there may be equilibria where the tax redistributes from poor to rich. The last section contains short conclusions. Some of the detail of the analysis is relegated to the Appendix.

\section{The Model}

We use a very simple model in order to illustrate the basic idea. The economy consists of three risk neutral individuals, who differ with respect to their pretax income level, given by $y_{1}>y_{2}>y_{3}$. The assumption of risk neutrality is not completely innocuous, an issue to which we return in Section 5.

There is a linear income tax with tax rate $t \in[0,1]$. However, a taxpayer may wish to hide her income. In the case of evasion, there is a fixed probability $p \in[0,1]$ that an individual will be audited and her true income will be known. Let $e$ be the amount evaded. In case of an audit, the individual 
pays tax on the true income, ty, plus a penalty of the form $s t e+F$, where $s$ is the penalty rate and $F$ a fixed fine.

The fixed cost should literally be interpreted as a fixed fine component. With a slight reinterpretation, however, one might also think of ore generally, the monetary equivalent of the costs of going to court, being put in jail, fixed "moral costs" of evasion, differing cheating opportunities due to employment situation, etc. Note that if speaking of non-monetary costs, $F$ should be interpreted as the monetary equivalent of the opportunity cost. In this case, however, the model would have to be slightly changed in that the government budget constraint should include the "real" fiscal transfer from the taxpayer, which may be nil as in the case of moral costs.

Tax proceeds are used to finance a per capita grant of $g$. Individuals are assumed to vote on the tax rate and transfer before evasion decisions are made.

An individual's expected net of tax income is therefore

$$
y_{i}^{n}=(1-t) y_{i}+g
$$

if she does not evade, and

$$
y_{i}^{e}=(1-t) y_{i}-p\left((1+s) t e_{i}+F\right)+(1-p) t e_{i}+g
$$

if she evades, where $e_{i}$ is the amount of income evaded. Expected income is denoted

$$
E Y_{i}=\max \left\{y_{i}^{n}, y_{i}^{e}\right\} .
$$

The assumption of risk neutrality implies that individuals evade either all or none of their income. In particular, an individual is indifferent between evading or not when

$$
y_{i}^{n}=y_{i}^{e} \Leftrightarrow t=\frac{p F}{(1-(1+s) p) y_{i}} \equiv t_{i} .
$$

Individuals will not evade any income when $t \leq t_{i}$ and their entire income when $t>t_{i}$. As long as $p, F>0$, there is a tax rate where all taxpayers honestly report their income. Equation (1) implies $\partial t_{i} / \partial y_{i}<0$ so that $t_{1}<t_{2}<t_{3}$.

The expected tax payment of an individual is

$$
T_{i}=\min \left\{t y_{i}, p\left((1+s) t y_{i}+F\right)\right\} .
$$


The assumptions made so far imply that individuals are only able to pay the fines imposed on them on average, but the actual fines may exceed the individual income. This is of course due to the assumption of risk neutrality. Literally, people would evade even if they were hung when caught cheating, if only the evasion gamble is fair. One might assume a small degree of risk aversion to make sure individuals would not evade when their entire income is taxed away in case of detection. This would imply that in equilibrium each individual will be able to pay her actual tax burden inclusive of the penalty. Another way to deal with this problem would be to impose an additional constraint on the level of fines (or impose individuals to evade only that fraction of income which leaves them enough to pay the fine). An alternative would be either to assume some tax exempt income high enough to pay the fine.

Voting takes place before evasion so expenditures must equal expected revenue. The government budget constraint is then

$$
g=\frac{1}{3} \sum_{i} T_{i} .
$$

Since all three individuals always evade either all or none of their income, the budget locus is piecewise linear, with kinks at the tax rates $t_{i}$ where one individual starts evading. Since individual $i$ is indifferent between evading or not at $t_{i}, T_{i}$ is the same whether he evades or not, but the slope $d T_{i} / d t$ is flatter when the individual evades, which implies a kink but no discontinuous jump at $t_{i}$.

\section{Voting}

Individuals vote for the tax rate which maximises their net income. We assume that voting is pairwise by simple majority.

Since expected net income is linear in $t$, attention can be restricted to a choice between five tax rates: $0, t_{1}, t_{2}, t_{3}$ and 1 . The following result establishes some properties of individual utility as a function of the tax rate.

Proposition 1 (i) Voter 1's utility is linearly decreasing on $\left[0, t_{1}\right]$ with marginal utility $\bar{y}-y_{1}$, linear on $\left[t_{1}, t_{2}\right]$ with marginal utility $-\frac{2}{3} p(1+s) y_{1}+\frac{1}{3}\left(y_{2}+y_{3}\right)$, linear on $\left[t_{2}, t_{3}\right]$ with marginal utility $-\frac{2}{3} p(1+s) y_{1}+\frac{1}{3}\left(p(1+s) y_{2}+y_{3}\right)$, linearly decreasing on $\left[t_{3}, 1\right]$ with marginal utility $p(1+s)\left(\bar{y}-y_{1}\right)$. 
(ii) Voter 2's utility is linear on $\left[0, t_{1}\right]$ with marginal utility $\bar{y}-y_{2}$, linear on $\left[t_{1}, t_{2}\right]$ with marginal utility $-\frac{2}{3} y_{2}+\frac{1}{3}\left(p(1+s) y_{1}+y_{3}\right)$, linear on $\left[t_{2}, t_{3}\right]$ with marginal utility $-\frac{2}{3} p(1+s) y_{2}+\frac{1}{3}\left(p(1+s) y_{1}+y_{3}\right)$, linear on $\left[t_{3}, 1\right]$ with marginal utility $p(1+s)\left(\bar{y}-y_{2}\right)$.

(iii) Voter 3's utility is linearly increasing on $\left[0, t_{1}\right]$ with marginal utility $\bar{y}-y_{3}$, linear on $\left[t_{1}, t_{2}\right]$ with marginal utility $-\frac{2}{3} y_{3}+\frac{1}{3}\left(p(1+s) y_{1}+y_{2}\right)$, linear on $\left[t_{2}, t_{3}\right]$ with marginal utility $-\frac{2}{3} y_{3}+\frac{1}{3} p(1+s)\left(y_{1}+y_{2}\right)$, linearly increasing on $\left[t_{3}, 1\right]$ with marginal utility $p(1+s)\left(\bar{y}-y_{3}\right)>0$.

Proof. Individual utility can be written

$$
-\frac{2}{3} T_{i}+\frac{1}{3} \sum_{j \neq i} T_{j} .
$$

Using the definition of $T_{i}$ and examining $T_{i}$ as function of the $t_{i}$ s gives the result.

Consider voter 2 to illustrate the redistributive nature of the tax system. For $0 \leq t \leq t_{1}$, utility is increasing if and only if $y_{2}<\bar{y}$. This is as in the standard model without evasion. For $t_{1} \leq t \leq t_{2}$, only voter 1 evades. Here, voter 2 does not necessarily benefit from higher taxes since these are paid by the rich only if expected fines are high enough. In fact, if $y_{2}>$ $\frac{1}{2}\left(p(1+s) y_{1}+y_{3}\right)$, the tax effectively redistributes from the middle class to the rich and poor. At $t_{2}$, voter 2 starts evading so marginal utility is higher than for $t_{1} \leq t \leq t_{2}$, and it is positive if $y_{2}<\frac{1}{2}\left(y_{1}+\frac{y_{3}}{p(1+s)}\right)$. This condition is likely to be satisfied if $y_{2}$ is small relative to $y_{3}$, and also if enforcement is sufficiently lax that redistribution is effectively from the poor to the middle class and rich. Finally, for $t \geq t_{3}$, all voters evade and voter 2 benefits from higher taxes if and only if $y_{2}<\bar{y}$.

Note that utility may not be single peaked and, hence, a voting equilibrium may fail to exist (see below). Figure 1 shows possible preferences for individual 2, where voter 2 prefers lower taxes for $t_{1}<t<t_{2}$ and higher taxes for $t>t_{2}$.

\section{Outcomes}

Since preferences are linear in tax rates, there are five alternative possible outcomes, namely, $t=0, t=t_{1}, t=t_{2}, t=t_{3}$, and $t=1$. Hence, each 


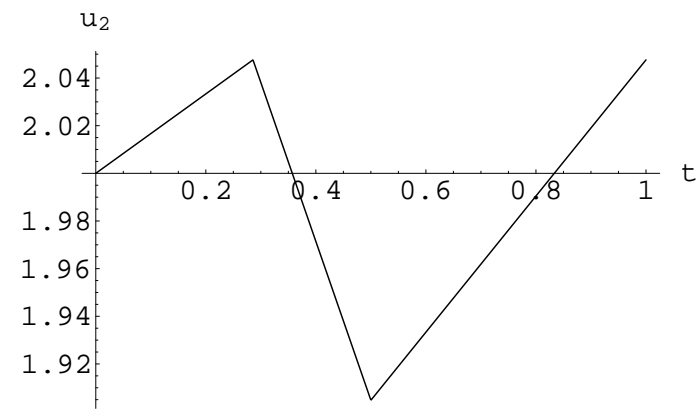

Figure 1: Voter 2's preferences over tax policy

individual has potentially 120 different preference profiles. This makes for $120^{3}=1,728,000$ possible outcomes. However, some of these individual preferences never occur: Individual 1 never prefers $t_{1}$ to 0 , and conversely, individual 3 never prefers 0 to $t_{1}$. We will further restrict the possibilities by assuming that $y_{2}<\bar{y}$, so that in line with many real world distributions, median income is below average. Further, suppose that individual 3's income is such that she never evades at any tax rate less than one for given enforcement parameters. ${ }^{2}$ This is also in line with the observation that some individuals never evade. ${ }^{3}$ Appendix A lists all possible individual preference profiles. From these, it is also possible to deduce certain relationships among these individual preferences (see Appendix B).

We now turn to a description of possible outcomes. First, it may be that no equilibrium exists. Second, an equilibrium may exist with "conventional" properties, namely, redistribution from rich to poor. Third, there may be equilibria which do not have conventional properties. These three possibilities are described with the help of examples in the next three subsections. The Appendix lists all possible outcomes.

\footnotetext{
${ }^{2}$ This implies $y_{3} \leq p F /(1-(1+s) p)$. For the computations, we assume this holds with equality.

${ }^{3}$ This is sometimes offered as a critique of the standard model of tax evasion, since one observes that individuals do not evade even when the odds are very good (for instance, typical numbers for the audit rate of 0.015 and penalty rate of 0.2 imply that at observed tax rates everyone should evade if there were no fixed fine). In terms of our model, we may interpret $F$ as a fixed moral cost. Thus, for some individuals the moral costs may be so high that they do not evade even when the probability of getting caught is low.
} 


\subsection{No Equilibrium}

Since individual preferences are not single peaked, the possibility of "voting cycles" arises. For instance, consider the parameters given by $s=0.2, F=$ $2, y_{1}=3.1, y_{2}=2, y_{3}=1$. This corresponds to Case 1 in Appendix B. Let $x \succ_{i} y$ denote "individual $i$ strictly prefers $x$ to $y$ ", and let $x \succ y$ denote " $x$ is preferred to $y$ by the majority of voters". The individual preferences are:

$$
\begin{array}{ll}
\text { Individual 1: } & 0 \succ_{1} t_{2} \succ_{1} t_{1} \succ_{1} 1 \\
\text { Individual 2: } & 1 \succ_{2} t_{1} \succ_{2} 0 \succ_{2} t_{2} \\
\text { Individual 3: } & t_{2} \succ_{2} 1 \succ_{2} t_{1} \succ_{2} 0 .
\end{array}
$$

A voting cycle occurs:

$$
t_{2} \succ 1 \succ t_{1} \succ 0 \succ t_{2} .
$$

\section{2 "Conventional" Equilibria}

There are also cases where an equilibrium exists which is "conventional" since it has the properties of the RRMR model. For instance, let $s=0.1, F=$ $0.25, y_{1}=4, y_{2}=2, y_{3}=1$. This corresponds to Case 14 listed in Appendix B. Individual preferences are as follows:

$$
\begin{array}{ll}
\text { Individual 1: } & 0 \succ_{1} t_{1} \succ_{1} t_{2} \succ_{1} 1 \\
\text { Individual 2: } & 1 \succ_{2} t_{2} \succ_{2} t_{1} \succ_{2} 0 \\
\text { Individual 3: } & 1 \succ_{3} t_{2} \succ_{3} t_{1} \succ_{3} 0 .
\end{array}
$$

Obviously, individuals 2 and 3 have the same preferences and their preferred tax rate of 1 is the Condorcet winner. This conforms to the equilibrium without evasion. However, here, all three individuals evade. ${ }^{4}$ But redistribution is still from rich to poor, since the expected fines are proportional to income and these are redistributed lump sum.

If $y_{1}$ is very large, then any gains individual 1 may have by evading are swamped by the redistributive effect. Likewise, if voters 1 and 2 are poor enough, they always prefer more redistribution to less.

\footnotetext{
${ }^{4}$ Individual 3 has been assumed to be indifferent between evading or not.
} 


\section{3 "Unconventional" Equilibria}

Some equilibria have interesting properties. Consider the parameters: $s=$ $0.3, F=3, y_{1}=3.1, y_{2}=2.4, y_{3}=2$. This corresponds to Case 11 listed in Appendix B. Preferences over the tax rates are as follows:

$$
\begin{array}{ll}
\text { Individual 1: } & 0 \succ_{1} 1 \succ_{1} t_{2} \succ_{1} t_{1} \\
\text { Individual 2: } & t_{1} \succ_{2} 1 \succ_{2} t_{2} \succ_{2} 0 \\
\text { Individual 3: } & t_{1} \succ_{3} t_{2} \succ_{3} 1 \succ_{3} 0 .
\end{array}
$$

Since both individual 1 and 2 have $t_{1}=0.65$ as their preferred tax rate, this is the Condorcet winner. ${ }^{5}$ This equilibrium is "conventional" in the sense that the distributional conflict is between the rich on the one side and the poor and middle class on the other. However, the rich are not extremely rich, so they would benefit from taxation in the range where they start to evade. The poor and middle class would lose. Hence, in this equilibrium, no one evades, and the possibility of evasion limits redistribution.

Now, suppose that $s=0.4, F=3, y_{1}=3.1, y_{2}=1.4, y_{3}=1$. This corresponds to Case 7 listed in Appendix B. We then have:

$$
\begin{array}{ll}
\text { Individual 1: } & 0 \succ_{1} t_{2} \succ_{1} t_{1} \succ_{1} 1 \\
\text { Individual 2: } & 1 \succ_{2} t_{1} \succ_{2} t_{2} \succ_{2} 0 \\
\text { Individual 3: } & t_{2} \succ_{3} 1 \succ_{3} t_{1} \succ_{3} 0 .
\end{array}
$$

It can be checked that $t_{2}=0.74$ is now a Condorcet winner, i.e., beats any other alternative in a pairwise contest.

Note that over the region $t_{1} \leq t<t_{2}$, both 1 and 3's utility is increasing, while 2's utility is decreasing. The explanation is that $p$ and $s$ are low enough that the expected tax payment for 1 is lower than the per capita grant, hence, in this region, he benefits from redistribution. So does 3 whose income is low enough for him to benefit from the combined certain tax payment of 2 and uncertain tax payment of 1 . Voter 2, however, has income which is high enough that he redistributes both towards 3 who has low income and towards 1 who does not pay taxes.

\footnotetext{
${ }^{5}$ Note that the fixed fine exceeds the income of taxpayers 2 and 3 , but in equilibrium only individual 1 evades.
} 
Locally, the tax system redistributes from the middle class (who pay taxes) to the poor (who also pay taxes but have lower incomes) and to the rich (who have high income but do not pay taxes). Stigler (1970) formulated "Director's law" of income redistribution: the hypothesis that redistribution would go from the poor and rich to the middle class. ${ }^{6}$ The result we presented here is also of the "ends against the middle" type (Epple and Romano, 1996b), but Director's law is stood on its head, because redistribution goes from, not to the middle class.

\section{$5 \quad$ Risk Averse Individuals}

I now briefly discuss how relaxing the simplifying assumption of risk neutrality affects the basic results. Let individuals have utility functions $u(c$, $u^{\prime}>0>u^{\prime \prime}$, which implies risk aversion. Expected utility is of the form

$$
E u=p u((1-t) y-(1-a+a t) s e-\delta F+g)+(1-p) u((1-t) y+t e+g),
$$

where $a \in[0,1]$. This encompasses the case originally analyzed by Allingham and Sandmo (1972), where the fine is proportional to income evaded $(a=0)$, and the case considered by Yitzhaki (1973), where fines are proportional to evaded tax $(a=1) . \delta$ is a dummy variable equal to one if the taxpayer evades and zero otherwise. Let $b=1-a+a t$. Define $u_{0}:=u((1-t) y+g)$ and $\Delta:=E u-u_{0}$.

The first order condition for an interior solution to (15) is

$$
\phi:=-p b s u_{d}^{\prime}+(1-p) t u_{n}^{\prime}=0 .
$$

The second order condition is

$$
p(b s)^{2} u_{d}^{\prime \prime}+(1-p) t^{2} u_{n}^{\prime \prime}<0 .
$$

Provided $\Delta>0, e=0$ if $\phi<0$ and $e=y$ if $\phi>0$.

With $F>0$, risk aversion implies that $\Delta<0$ if $t=0$. Hence, there is a tax rate $t_{i}$ where individual $y_{i}$ is just indifferent between evading or not evading. Formally, $t_{i}=\min \hat{t}_{i}$, where $\hat{t}_{i}$ solves $\Delta=0$.

\footnotetext{
${ }^{6}$ This property appears in models of public provision of private goods, where redistribution may go from the poor and rich to the middle class (Epple and Romano, 1996b). However, Fernandez and Rogerson (1995) present an example of education subsidies where redistribution is from the poor to the middle class and rich.
} 
From the discussion in the previous sections, we know that with risk neutrality, $t_{i}$ is decreasing in income. For the general case, this will hold in certain circumstances, e.g., if the degree of risk aversion is sufficiently low and individuals evade a large fraction of their income. This possibility will be used below to examine voting equilibria.

In particular, in the absence of single peakedness it is convenient to check the single crossing property (Gans and Smart, 1996). Define an individual's indifference curve in $g, t$ space as those combinations of tax rate and transfer which give the individual the same utility. From (15), the slope of an indifference curve is

$$
\sigma=\left.\frac{d g}{d t}\right|_{\bar{U}}=\begin{array}{lll}
y & \text { if } & t<t_{i} \\
y-\frac{(1-a) s}{s(1-a(1-t))+t} e & \text { if } & t \geq t_{i}
\end{array}
$$

use having been made of (16). Note that (17) holds for an interior optimum.

In general, the slope of the indifference curve then depends on whether or not the individual evades. The case analysed so far corresponds to $a=1$, which was the form assumed by Yitzhaki (1973). Examining (17), we find that in this case the slope of the indifference curve is $y$ if evasion is at an interior optimum. Since the single crossing property holds in this case, it is immediately clear that the median income earner is decisive (Gans and Smart, 1996). Further, richer individuals prefer lower taxes, so the properties are essentially those of the RRMR model. See Figure 2.

However, the possibility of corner solutions makes the analysis more difficult. In particular, with $a=1$, we get $\sigma=y$ for $e<y$. For individuals who would like to evade more than their entire income, the slope is less than $y$. Single crossing may not hold in this case, since the indifference curve of a rich individual who evades his entire income may be flatter than that of a poor individual who evades less than the entire income. ${ }^{7}$

$a=0$ corresponds to the original version used by Allingham and Sandmo (1972). The slope of the indifference curve with evasion then simplifies to $y-\frac{s}{s+t} e$. An equilibrium could be shown to exist if the slope were increasing in $y$ in this range and if the tax rate at which an individual starts evading were the same for everyone. The slope, however, may be decreasing in income if richer individuals evade a larger fraction of their income, which is the case

\footnotetext{
${ }^{7}$ This may seem like a theoretical possibility. But occasionally taxpayers do not declare any income at all. A notable case is that of former German tennis star Steffi Graf who reportedly did not even file a tax return for four years.
} 


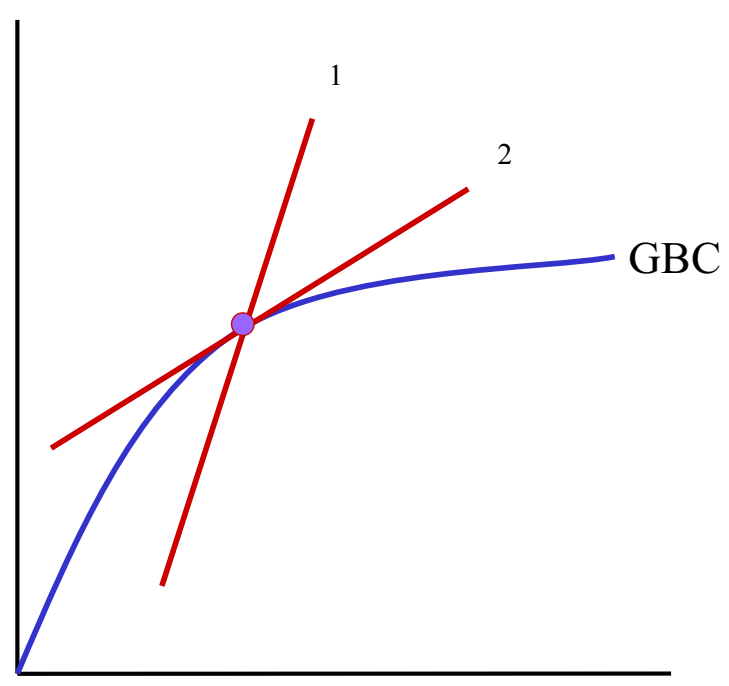

Figure 2: Single crossing

if relative risk aversion is decreasing in income. Second, for $F>0$, if $t_{i}$ is decreasing in $y$, single crossing cannot be ensured (see Figure 3 ). Here single crossing is assumed to hold in the regions where either both taxpayers pay taxes or both evade. $y_{1}>y_{2}$ implies that $y_{1}$ 's indifference curve is steeper. However, $t_{1}<t_{2}$ implies that indifference curves may cross twice as shown. This implies that an equilibrium need not exist. Further, it is also possible that a richer individual prefers a higher tax rate than a poorer one, at the margin.

We summarize the results as follows.

Proposition 2 Let $F>0$ and let individuals be risk averse. If $a<1$ or $a=1$ and $e=y$, single crossing does not hold. If $a=1$ and $e<y$, the median income earner is decisive and richer individuals prefer less redistribution.

Again, there are many possible outcomes. Instead of a complete characterization, we provide an example with an interesting equilibrium, one which 


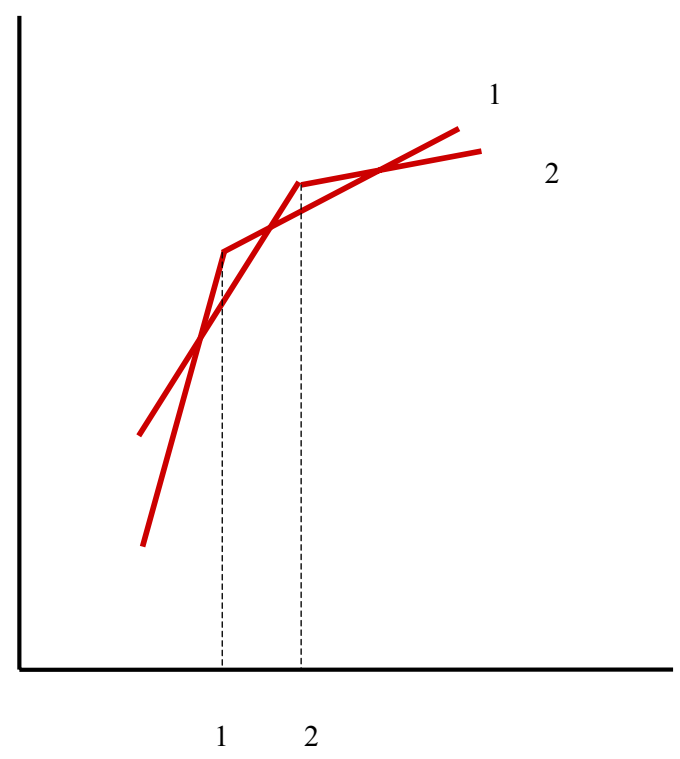

Figure 3: No single crossing

also differs from those described above.

Example Let utility be given by $u=\ln \left(c-c_{0}\right)$, where $c_{0}>0$. This function displays decreasing absolute and relative risk aversion. Let $a=0.5$, and $y_{1}=10, y_{2}=12, y_{3}=15$. The other parameters are: $s=0.2, p=0.015, F=$ $2, c_{0}=2$. The three voters' preferences are shown in Figure 4. Individual 1's utility is first falling, then concave with a maximum at $\hat{t}_{1}=0.6$. Individual 2 's utility is first concave with a local maximum at $\tilde{t}_{2}=0.004$, then concave with a global maximum at $\hat{t}_{2}=0.55$, and lastly increasing. Individual 3's utility is concave with a local maximum at 0.0041 , then increasing with a global maximum at 1 . The equilibrium tax rate is $\hat{t}_{2}$. While voters 1 and 2 evade their entire income, voter 3 evades only 72 percent.

Note that in this example, redistribution is from poor to rich rather than from the middle class to the rich and poor: the richest individual pays taxes 
(inclusive of expected fines) of 1.26 percent of her income, the middle income voter 1.31 and the poorest voter 16.5 percent. For a similar example in the case of education policy, see Fernandez and Rogerson (1995). There, the rich

and middle class vote for education subsidies, which are financed also by the poor who do not benefit from them since their income is too low to purchase education even with the subsidies.

\section{Conclusion}

In this paper, we have analysed how the possibility of tax evasion affects voting on redistribution. The model has shown that the implications of tax evasion are not trivial. Equilibria do not need to exist under standard assumptions on preferences. When they do exist, they may have properties which differ from conventional voting models. In particular, redistribution may not go from rich to poor but instead from the middle class to the rich and poor.

The model was simplistic in some of its assumptions, for instance, risk neutrality, linear tax and penalty system. We briefly discussed how risk aversion affects the analysis. Introducing more complex tax and enforcement policies would make the analysis more complicated, but there would be a range where the basic results continue to hold. Another interesting extension might be to allow individuals to choose work in the black economy. Declared income then depends on the decision of how much to work in the legal and illegal sectors. Assuming that there are fixed costs of taking up work in the black economy, one would find similar conclusions to those discussed here, although the nature of the work-leisure tradeoff makes the problem more complicated (see, e.g., Cowell, 1990 for a discussion.)

The model also has some other implications. For instance, empirical estimates of tax evasion should treat tax rates as endogenous. Second, the interaction of tax and audit rates with evasion is also more complicated when voting is taken into account (Borck, 2002). Suppose the tax authority sets audit rates and voters choose the tax rate. Then increased auditing may cause voters to vote for higher tax rates, which in turn may lead to more evasion. 


\section{Acknowledgments}

Previous versions of this paper were presented at the European Public Choice Conference in Siena, the Verein für Socialpolitik in Innsbruck and seminars at Humboldt University and DIW in Berlin. I would like to thank seminar participants as well as Pio Baake for helpful comments and suggestions.

\section{Appendix}

\section{A Individual Preferences}

With four alternatives, each individual has $4 !=24$ possible preference profiles (see Table 2). This implies a total of $24^{3}=13824$ possible combinations of the three individuals preferences. Eliminating those which cannot occur, however, narrows down the set of potential outcomes.

We first insert the different tax rates into the individuals' utility functions, and denote the resulting utility levels $u_{i 0}, \ldots, u_{i 3}$, where $i$ stands for individual $i$ and $0, \ldots, 3$ for tax rates from 0 to 1 in ascending order. All computations assume that $p=\frac{y_{3}}{F+(1+s) y_{3}}$ so individual 3 never evades at any tax rate $t<1$. The corresponding utility levels are shown in Table 1.

From these utility levels, we can find critical income levels, which will be labelled $y_{i}^{j k}$, such that voter $i$ prefers alternative $j$ to $k$ if and only if $y>y_{i}^{j k}$ :

$$
\begin{aligned}
& u_{10}>u_{11} \quad \Leftrightarrow \quad y_{1}>y_{1}^{01}:=\frac{y_{2}+y_{3}}{2} \\
& u_{10}>u_{12} \quad \Leftrightarrow \quad y_{1}>y_{1}^{02}:=\frac{F\left(y_{3}-y_{2}\right)+(1+s) y_{3}\left(y_{2}+y_{3}\right)}{2(1+s) y_{3}} \\
& u_{10}>u_{13} \quad \Leftrightarrow \quad y_{1}>y_{1}^{03}:=\frac{y_{2}+y_{3}}{2} \\
& u_{11}>u_{12} \quad \Leftrightarrow \quad y_{1}>y_{1}^{12}:=\frac{\left(y_{2}+y_{3}\right)\left(F+(1+s) y_{3}\right)}{2(1+s) y_{3}} \\
& u_{11}>u_{13} \quad \Leftrightarrow \quad y_{1}>y_{1}^{13}:=\frac{F+(1+s) y_{3}}{1+s} \\
& u_{12}>u_{13} \quad \Leftrightarrow \quad y_{1}>y_{1}^{23}:=\frac{F+(1+s)\left(y_{2}+y_{3}\right)}{2(1+s)} .
\end{aligned}
$$




$$
\begin{aligned}
& u_{22}>u_{21} \quad \Leftrightarrow \quad y_{2}>y_{2}^{01}:=\frac{y_{1}+y_{3}}{2} \\
& u_{20}>u_{22} \quad \Leftrightarrow \quad y_{2}>y_{2}^{02}:=\frac{y_{3}\left(F+(1+s)\left(y_{1}+y_{3}\right)\right)}{F+2(1+s) y_{3}} \\
& u_{20}>u_{23} \Leftrightarrow y_{2}>y_{2}^{03}:=\frac{y_{1}+y_{3}}{2} \\
& u_{21}>u_{22} \quad \Leftrightarrow \quad y_{2}>y_{2}^{12}:=\frac{y_{3}\left(F+(1+s)\left(y_{1}+y_{3}\right)\right)}{2\left(F+(1+s) y_{3}\right)} \\
& u_{21}>u_{23} \Leftrightarrow F>(1+s)\left(y_{1}-y_{3}\right) \\
& u_{22}>u_{23} \Leftrightarrow y_{2}>y_{2}^{23}:=\frac{F+(1+s)\left(y_{1}+y_{3}\right)}{2(1+s)} . \\
& u_{30}>u_{31} \Leftrightarrow y_{3}>y_{3}^{01}:=\frac{y_{1}+y_{2}}{2} \\
& u_{30}>u_{32} \quad \Leftrightarrow \quad y_{3}>y_{3}^{02}:=\frac{1}{2}\left(p_{3}(1+s)\left(y_{1}-y_{2}\right)+2 y_{2}\right) \\
& u_{30}>u_{33} \Leftrightarrow y_{3}>y_{3}^{03}:=\frac{y_{1}+y_{2}}{2} \\
& u_{31}>u_{32} \quad \Leftrightarrow \quad y_{3}>y_{3}^{12}:=\frac{1}{2}\left(p_{3}(1+s) y_{1}+y_{2}\right) \\
& u_{31}>u_{33} \quad \Leftrightarrow \quad y_{3}>y_{3}^{13}:=\frac{(1+s) y_{1}-F}{1+s)} \\
& u_{32}>u_{33} \Leftrightarrow y_{3}>y_{3}^{23}:=\frac{(1+s)\left(y_{1}+y_{2}\right)-2 F}{2(1+s)} .
\end{aligned}
$$

Individual 1 We can rank the critical income levels $y_{1}^{02}<y_{1}^{03}=\frac{1}{2}\left(y_{2}+y_{3}\right)<$ $y_{1}^{23}<y_{1}^{12}$, and $y_{1}^{13}<y_{1}^{12}$. (1) Since $y_{1}>\bar{y}$, we know that $0 \succ_{1} t_{1}$, which excludes $7-12,15,16,18,21,22,24$. (2) $y_{1}>y_{1}^{03}>y_{1}^{02}$ implies $0 \succ_{1} 1$ and $0 \succ_{1} t_{2}$. This excludes $13-24$. (3) $y_{1}^{12}>y_{1}^{23}$ implies $t_{1} \succ_{1} t_{2} \Rightarrow t_{2} \succ_{1} 1$. This excludes 2 and 5. This leaves $1,3,4$, and 6 as possible preferences. 1 holds if $y_{1}>y_{1}^{12}, 3$ if $y_{1}^{23}<y_{1}<y_{1}^{12}$ and $y_{1}>y_{1}^{13}, 4$ if $y_{1}^{23}<y_{1}<y_{1}^{12}$ and $y_{1}<y_{1}^{13}$, and 6 if $y_{1}<y_{1}^{23}$ and $y_{1}<y_{1}^{13}$.

Individual 2 For individual 2, we have $y_{2}^{12}<y_{2}^{02}<y_{2}^{03}=\frac{1}{2}\left(y_{1}+y_{3}\right)<y_{2}^{23}$. (1) $y_{2}<\bar{y}$ implies $y_{2}<y_{2}^{03}$, which implies $1 \succ_{2} 0$, and $1 \succ_{2} t_{2}$ as well as $t_{1} \succ_{2} 0$. This excludes $1-10,13-18,19,20$, and 23. This leaves $11,12,21,22$, and 24 . 11 obtains if $y_{2}>y_{2}^{02}$ and $F>(1+s)\left(y_{1}-y_{3}\right), 12$ if $y_{2}^{12}<y_{2}<y_{2}^{02}$ and $F>(1+s)\left(y_{1}-y_{3}\right)$, 24 obtains if $y_{2}<y_{2}^{12}$ and $F<(1+s)\left(y_{1}-y_{3}\right), 22$ if $y_{2}^{12}<y_{2}<y_{2}^{02}$ and $F<(1+s)\left(y_{1}-y_{3}\right)$, and 21 if $y_{2}^{02}<y_{2}$ and $F<(1+s)\left(y_{1}-y_{3}\right)$. 
Individual 3 For individual 3, we obtain $y_{3}^{23}<y_{3}^{12}<y_{3}^{02}>y_{2}, y_{3}^{23}<y_{3}^{13}<$ $y_{3}^{03}=\frac{1}{2}\left(y_{1}+y_{2}\right)<y_{3} 02$, and $y_{3}^{13}<y_{3}^{12}$. (1) From $y_{3}<y_{2}<\bar{y}$, we have $t_{1} \succ_{3} 0$, $t_{2} \succ_{3} 0$, and $1 \succ_{3} 0$. This eliminates $1-9,11,13-15,17,19-21$ and 23. (2) $y_{3}^{23}<y_{3}^{12}$ implies $1 \succ_{3} t_{2} \Rightarrow t_{2} \succ_{3} t_{1}$, and $y_{3}^{23}<y_{3}^{13}$ implies $1 \succ_{3} t_{2} \Rightarrow 1 \succ_{3} t_{1}$. This eliminates 12 and 22. This leaves profiles 10,16,18, and 24. 10 obtains if $y_{3}>y_{3}^{12}, 16$ if $y_{3}^{23}<y_{3}<y_{3}^{12}, y_{3}>y_{3}^{13}, 18$ if $y_{3}^{23}<y_{3}<y_{3}^{13}$, and finally, 24 if $y_{3}<y_{3}^{23}$.

\section{B Aggregation of Preferences}

From the individual preferences, we can infer some relationships among the individuals' preferences.

(1) $y_{1} \leq y_{1}^{23}$ implies $y_{2}<y_{2}^{12}$ iff $y_{2}<\left(3 y_{3}\left(F+(1+s) y_{3}\right) /\left(4 F+3(1+s) y_{3}\right)<y_{3}\right.$, so $1 \succ_{1} t_{2} \Rightarrow t_{1} \succ_{2} t_{2}$.

(2) $y_{1}>y_{1}^{12}$ implies $y_{3}>y_{3}^{12}$ iff $y_{3}>y_{2}$, so $t_{1} \succ_{1} t_{2} \Rightarrow t_{2} \succ_{3} t_{1}$.

(3) Since $y_{1}<\bar{y}>y_{2}>y_{3}$, we have $t_{1} \succ_{1} 1$ iff $y_{1}>y_{3}+F /(1+s)$, which implies $1 \succ_{2} t_{1}$ and $1 \succ_{3} t_{1}$.

(4) $y_{1}<y_{1}^{12}$ implies $y_{2}^{12}=\frac{y_{3}\left(F+(1+s)\left(y_{1}+y_{3}\right)\right)}{2\left(F+(1+s) y_{3}\right)}<\frac{1}{4}\left(y_{2}+3 y_{3}\right)$, where the last inequality follows from substituting $y_{1}=y_{1}^{12}$ into $y_{2}^{12}$, since this expression is increasing in $y_{1}$. Solving $y_{2}<\frac{1}{4}\left(y_{2}+3 y_{3}\right)$ gives $y_{2}<y_{3}$, a contradiction. Hence, $y_{1}<y_{1}^{12}$ implies $y_{2}>y_{2}^{12}$.

(5) $y_{1}<y_{1}^{13}$ implies $y_{2}^{12}<y_{3}$. Therefore, $y_{1}<y_{1}^{13}$ implies $y_{2}>y_{2}^{12}$.

(6) $y_{1}<y_{1}^{13}$ implies $y_{3}>y_{3}^{13}$ and $u_{21}<u_{23}$.

All remaining possibilities and the resulting outcomes are shown in Table 3.

\section{References}

Allingham, M. G. and A. Sandmo (1972). Income tax evasion: A theoretical analysis. Journal of Public Economics 1, 323-338.

Alm, J., I. Sanchez, and A. de Juan (1995). Economic and noneconomic factors in tax compliance. Kyklos 48, 3-18.

Andreoni, J., B. Erard, and J. Feinstein (1998). Tax compliance. Journal of Economic Literature XXXVI, 818-860.

Borck, R. (2002). Stricter enforcement may increase tax evasion. discussion paper 297, DIW Berlin.

Cowell, F. A. (1990). Cheating the Government: The Economics of Evasion. Cmabridge, Mass.: MIT Press. 
Cowell, F. A. and J. P. F. Gordon (1988). Unwillingenss to pay: Tax evasion and public good provision. Journal of Public Economics 36, 305-321.

Epple, D. and R. Romano (1996a). Public provision of private goods. Journal of Political Economy 104, 57-84.

Epple, D. and R. E. Romano (1996b). Ends against the middle: Determining public service provision when there are private alternatives. Journal of Public Economics 62, 297-325.

Falkinger, J. (1991). On optimal public good provision with tax evasion. Journal of Public Economics 45, 127-33.

Feld, L. P. and J.-R. Tyran (2002). Tax evasion and voting: An experimental analysis. Kyklos 55, 197-222.

Fernandez, R. and R. Rogerson (1995). On the political economy of education subsidies. Review of Economic Studies 62, 249-262.

Gans, J. S. and M. Smart (1996). Majority voting with single-crossing preferences. Journal of Public Economics 59, 219-237.

Meltzer, A. H. and S. F. Richard (1981). A rational theory of the size of government. Journal of Political Economy 89, 914-927.

Mirrlees, J. A. (1971). An exploration in the theory of optimal income taxation. Review of Economic Studies 38, 175-208.

Roberts, K. W. (1977). Voting over income tax schedules. Journal of Public Economics 8, 329-340.

Roine, J. (1999). Tax avoidance, redistribution and voting. Mimeo, Stockholm University.

Romer, T. (1975). Individual welfare, majority voting, and the properties of a linear income tax. Journal of Public Economics 4, 163-185.

Slemrod, J. (1994). Fixing the leak in Okun's bucket: Optimal tax progressivity when avoidance can be controlled. Journal of Public Economics 55, 41-51.

Slemrod, J. and S. Yitzhaki (2000). Tax avoidance, evasion, and administration. In A. Auerbach and M. Feldstein (Eds.), Handbook of Public Economics. Amsterdam: Elsevier. Forthcoming.

Stigler, G. J. (1970). Director's law of public income redistribution. Journal of Law and Economics 13, 1-10.

Yitzhaki, S. (1973). A note on income tax evasion: A theoretical analysis. Journal of Public Economics 3, 201-202. 

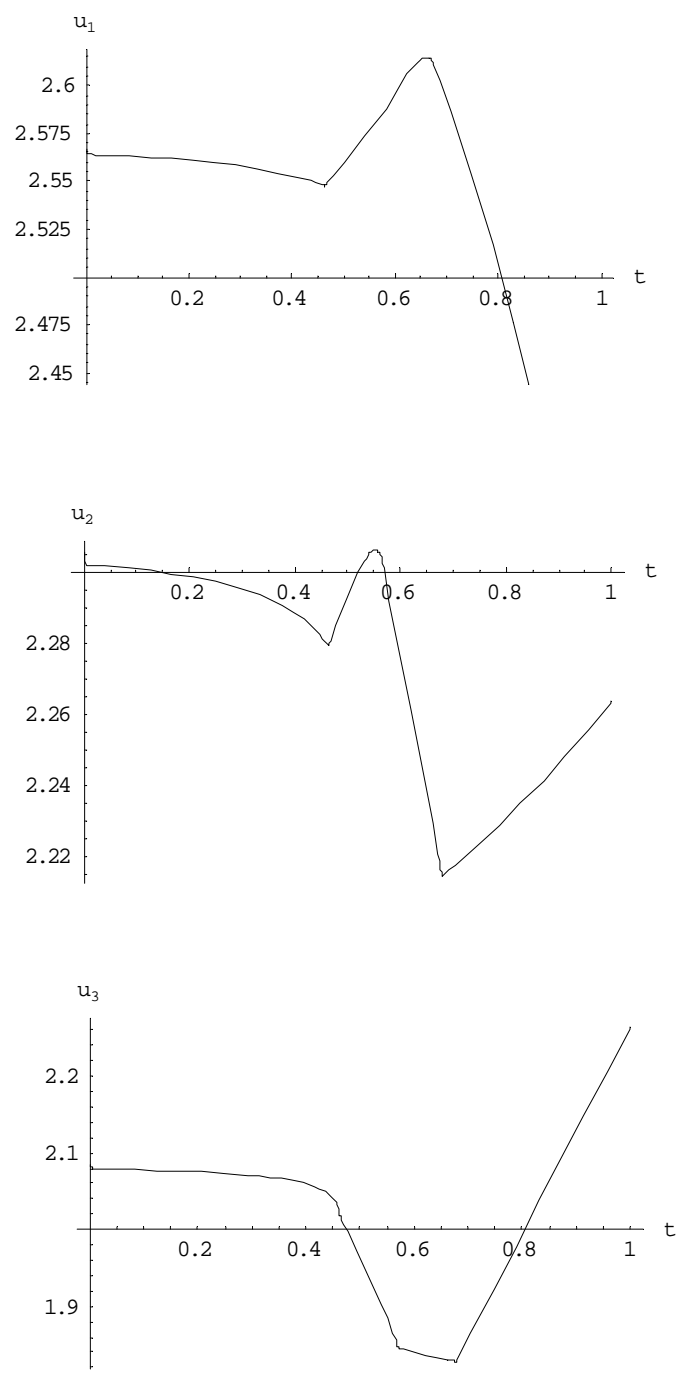

Figure 4: Voter preferences in Example 5 
Table 1: Voter utility at different tax rates

\begin{tabular}{ccccc}
\hline & $t=0(0)$ & $t=t_{1}(1)$ & $t=1(3)$ & $t=t_{2}(2)$ \\
$u_{1 i}$ & $y_{1}$ & $\frac{3 y_{1}^{2}-2 y_{1} y_{3}+y_{3}\left(y_{2}+y_{3}\right)}{3 y_{1}}$ & $\frac{F\left(3 y_{1} y_{2}+y_{3}\left(y_{3}-y_{2}\right)\right)+(1+s) y_{3}\left(y_{1}\left(3 y_{2}-2 y_{3}\right)+y_{3}\left(y_{2}+y_{3}\right)\right)}{3 y_{2}\left(F+(1+s) y_{3}\right)}$ & $\frac{3 F y_{1}+(1+s) y_{3}\left(y_{1}+y_{2}+y_{3}\right)}{3\left(F+(1+s) y_{3}\right)}$ \\
$u_{2 i}$ & $y_{2}$ & $\frac{3 y_{1} y_{2}+y_{1} y_{3}-2 y_{3} y_{2}+y_{3}^{2}}{3 y_{1}}$ & $\frac{F\left(3 y_{2}^{2}+y_{3}\left(y_{3}-y_{2}\right)\right)+(1+s) y_{3}\left(3 y_{2}^{2}-2 y_{2} y_{3}+y_{3}\left(y_{1}+y_{3}\right)\right)}{3 y_{2}\left(F+(1+s) y_{3}\right)}$ & $\frac{3 F y_{2}+(1+s) y_{3}\left(y_{1}+y_{2}+y_{3}\right)}{3\left(F+(1+s) y_{3}\right)}$ \\
$u_{3 i}$ & $y_{3}$ & $\frac{4 y_{1}^{2}-y_{2}-2 y_{3}}{3 y_{1}}$ & $\frac{F y_{3}\left(5 y_{2}-2 y_{3}\right)+(1+s) y_{3}\left(y_{1}+4 y_{2}-2 y_{3}\right) y_{3}}{3 y_{2}\left(F+(1+s) y_{3}\right)}$ & $\frac{3 F y_{3}+(1+s) y_{3}\left(y_{1}+y_{2}+y_{3}\right)}{3\left(F+(1+s) y_{3}\right)}$ \\
\hline \hline
\end{tabular}

Table 2: Possible Individual Preference Profiles

\begin{tabular}{ll}
\hline 1. & $0 \succ t_{1} \succ t_{2} \succ 1$ \\
2. & $0 \succ t_{1} \succ 1 \succ t_{2}$ \\
3. & $0 \succ t_{2} \succ t_{1} \succ 1$ \\
4. & $0 \succ t_{2} \succ 1 \succ t_{1}$ \\
5. & $0 \succ 1 \succ t_{1} \succ t_{2}$ \\
6. & $0 \succ 1 \succ t_{2} \succ t_{1}$ \\
7. & $t_{1} \succ 0 \succ t_{2} \succ 1$ \\
8. & $t_{1} \succ 0 \succ 1 \succ t_{2}$ \\
9. & $t_{1} \succ t_{2} \succ 0 \succ 1$ \\
10. & $t_{1} \succ t_{2} \succ 1 \succ 0$ \\
11. & $t_{1} \succ 1 \succ 0 \succ t_{2}$ \\
12. & $t_{1} \succ 1 \succ t_{2} \succ 0$ \\
13. & $t_{2} \succ 0 \succ t_{1} \succ 1$ \\
14. & $t_{2} \succ 0 \succ 1 \succ t_{1}$ \\
15. & $t_{2} \succ t_{1} \succ 0 \succ 1$ \\
16. & $t_{2} \succ t_{1} \succ 1 \succ 0$ \\
17. & $t_{2} \succ 1 \succ 0 \succ t_{1}$ \\
18. & $t_{2} \succ 1 \succ t_{1} \succ 0$ \\
19. & $1 \succ 0 \succ t_{1} \succ t_{2}$ \\
20. & $1 \succ 0 \succ t_{2} \succ t_{1}$ \\
21. & $1 \succ t_{1} \succ 0 \succ t_{2}$ \\
22. & $1 \succ t_{1} \succ t_{2} \succ 0$ \\
23. & $1 \succ t_{2} \succ 0 \succ t_{1}$ \\
24. & $1 \succ t_{2} \succ t_{1} \succ 0$ \\
\hline \hline
\end{tabular}


Table 3: Voting outcomes

\begin{tabular}{|c|c|c|c|c|}
\hline Parameter restrictions & Individual 1 & Individual 2 & Individual 3 & Equilibrium \\
\hline \multicolumn{5}{|l|}{ A. $y_{2}>y_{2}^{02}, F<(1+s)\left(y_{1}-y_{3}\right)$} \\
\hline Case 1. $y_{1}^{23}<y_{1}<y_{1}^{12}, y_{3}^{23}<y_{3}<y_{3}^{12}$ & $0 \succ t_{2} \succ t_{1} \succ 1$ & $1 \succ t_{1} \succ 0 \succ t_{2}$ & $t_{2} \succ 1 \succ t_{1} \succ 0$ & Cycle \\
\hline Case 2. $y_{1}^{23}<y_{1}<y_{1}^{12}, y_{3}<y_{3}^{23}$ & $0 \succ t_{2} \succ t_{1} \succ 1$ & $1 \succ t_{1} \succ 0 \succ t_{2}$ & $1 \succ t_{2} \succ t_{1} \succ 0$ & 1 \\
\hline \multicolumn{5}{|l|}{ B. $y_{2}>y_{2}^{02}, F>(1+s)\left(y_{1}-y_{3}\right)$} \\
\hline Case 3. $y_{1}^{23}<y_{1}<y_{1}^{12}, y_{3}>y_{3}^{12}$ & $0 \succ t_{2} \succ 1 \succ t_{1}$ & $t_{1} \succ 1 \succ 0 \succ t_{2}$ & $t_{1} \succ t_{2} \succ 1 \succ 0$ & $t_{1}$ \\
\hline Case 4. $y_{1}<y_{1}^{23}, y_{3}>y_{3}^{12}$ & $0 \succ 1 \succ t_{2} \succ t_{1}$ & $t_{1} \succ 1 \succ 0 \succ t_{2}$ & $t_{1} \succ t_{2} \succ 1 \succ 0$ & $t_{1}$ \\
\hline \multicolumn{5}{|l|}{ C. $y_{2}^{12}<y_{2}<y_{2}^{02}, F<(1+s)\left(y_{1}-y_{3}\right)$} \\
\hline Case 5. $y_{1}>y_{1}^{12}, y_{3}^{23}<y_{3}<y_{3}^{12}$ & $0 \succ t_{1} \succ t_{2} \succ 1$ & $1 \succ t_{1} \succ t_{2} \succ 0$ & $t_{2} \succ 1 \succ t_{1} \succ 0$ & Cycle \\
\hline Case 6. $y_{1}>y_{1}^{12}, y_{3}<y_{3}^{23}$ & $0 \succ t_{1} \succ t_{2} \succ 1$ & $1 \succ t_{1} \succ t_{2} \succ 0$ & $1 \succ t_{2} \succ t_{1} \succ 0$ & 1 \\
\hline Case 7. $y_{1}^{23}<y_{1}<y_{1}^{12}, y_{3}^{23}<y_{3}<y_{3}^{12}$ & $0 \succ t_{2} \succ t_{1} \succ 1$ & $1 \succ t_{1} \succ t_{2} \succ 0$ & $t_{2} \succ 1 \succ t_{1} \succ 0$ & $t_{2}$ \\
\hline Case 8. $y_{1}^{23}<y_{1}<y_{1}^{12}, y_{3}<y_{3}^{23}$ & $0 \succ t_{2} \succ t_{1} \succ 1$ & $1 \succ t_{1} \succ t_{2} \succ 0$ & $1 \succ t_{2} \succ t_{1} \succ 0$ & 1 \\
\hline \multicolumn{5}{|l|}{ D. $y_{2}^{12}<y_{2}<y_{2}^{02}, F>(1+s)\left(y_{1}-y_{3}\right)$} \\
\hline Case 9. $y_{1}^{23}<y_{1}<y_{1}^{12}, y_{3}>y_{3}^{12}$ & $0 \succ t_{2} \succ 1 \succ t_{1}$ & $t_{1} \succ 1 \succ t_{2} \succ 0$ & $t_{1} \succ t_{2} \succ 1 \succ 0$ & $t_{1}$ \\
\hline Case 10. $y_{1}^{23}<y_{1}<y_{1}^{12}, y_{3}^{23}<y_{3}<y_{3}^{12}$ & $0 \succ t_{2} \succ 1 \succ t_{1}$ & $t_{1} \succ 1 \succ t_{2} \succ 0$ & $t_{2} \succ t_{1} \succ 1 \succ 0$ & $t_{2}$ \\
\hline Case 11. $y_{1}<y_{1}^{23}, y_{3}>y_{3}^{12}$ & $0 \succ 1 \succ t_{2} \succ t_{1}$ & $t_{1} \succ 1 \succ t_{2} \succ 0$ & $t_{1} \succ t_{2} \succ 1 \succ 0$ & $t_{1}$ \\
\hline Case 12. $y_{1}<y_{1}^{23}, y_{3}^{23}<y_{3}<y_{3}^{12}$ & $0 \succ 1 \succ t_{2} \succ t_{1}$ & $t_{1} \succ 1 \succ t_{2} \succ 0$ & $t_{2} \succ t_{1} \succ 1 \succ 0$ & Cycle \\
\hline \multicolumn{5}{|l|}{$E . y_{2}<y_{2}^{12}, F<(1+s)\left(y_{1}-y_{3}\right)$} \\
\hline Case 13. $y_{1}>y_{1}^{12}, y_{3}^{23}<y_{3}<y_{3}^{12}$ & $0 \succ t_{1} \succ t_{2} \succ 1$ & $1 \succ t_{2} \succ t_{1} \succ 0$ & $t_{2} \succ t_{1} \succ 1 \succ 0$ & $t_{2}$ \\
\hline Case 14. $y_{1}>y_{1}^{12}, y_{3}<y_{3}^{23}$ & $0 \succ t_{1} \succ t_{2} \succ 1$ & $1 \succ t_{2} \succ t_{1} \succ 0$ & $1 \succ t_{2} \succ t_{1} \succ 0$ & 1 \\
\hline
\end{tabular}

